\title{
Standing Stock, Agar Yield and Properties of Gracilaria salicornia Harvested along the Tanzanian Coast
}

\author{
A. S. Buriyo and A. K. Kivaisi \\ Botany Department, University of Dar es Salaam, P.O. Box 35060, Dar es Salaam, Tanzania
}

Key words: Gracilaria salicornia, agar, yield, productivity, biomass, Tanzania

\begin{abstract}
Seasonal biomass variation and agar yield of G. salicornia (C. Ag.) Dawson from Oyster Bay, Dar es Salaam, and Chwaka Bay, Zanzibar, were determined, and some properties of the agar examined. Mean biomass and canopy cover values ranged from $21-60 \mathrm{~g} / \mathrm{m}^{2}$ and $7-$ $20 \%$, respectively. The highest mean biomass and cover values were obtained during the SE monsoon. Agar yield varied from 13.7 to $30.2 \%$ (dry weight) and was highest during the dry NE monsoon period. Alkali treatment generally reduced agar yield by $25-56 \%$. Gel strength of the agar gels ranged between 118 and $251 \mathrm{~g} / \mathrm{cm}^{2}$ and was significantly higher during the NE monsoon period $(t=2.2 ; \mathrm{P}=0.04$ and $t=8.9 ; \mathrm{P}<<0.05)$ for samples collected from Oyster Bay and Chwaka Bay respectively). Mean gel strengths of native agar samples $\left(205 \pm 45 \mathrm{~g} / \mathrm{cm}^{2}\right)$ was about $42 \%$ of that of the standard agar used. The 3,6-anhydrogalactose content was highest during the rainy season (37.4-44.3\%) and tended to coincide with low gel strengths. Sulphate content varied between 0.5 and $2.8 \%$ in both populations. It was concluded that the best period for harvesting G. salicornia for agar production in Tanzania is the dry (NE monsoon) period.
\end{abstract}

\section{INTRODUCTION}

Gracilaria is one of the algal genera from which agar is extracted commercially (Lewis et al., 1990). and the main source of agar in the world (Oliveira et al., 2000). The algae are harvested by hand from natural populations in Spain, Portugal, Morocco, the Azores, California, Mexico, New Zealand, South Africa, India, Chile and Japan (Armisen, 1995). Currently, the commercial mariculture of agar-producing seaweeds is led by the production of Gracilaria chilensis Bird, McLachlan et Oliveira in Chile (Buschmann \& Correa, 2001). The seaweed has also been cultivated in China, Taiwan, Namibia, Venezuela, Mexico (Armisen, 1995), Indonesia and Vietnam (Oliveira et al., 2000).

Seven species of Gracilaria including $G$. cornea J. Agardh (previously known as G. crassa Harvey, Buriyo et al., in press), G. corticata J. Agardh, G. arcuata Zanardini, G. salicornia, G. edulis (J. Ag.) Silva, G. fergusoni J. Agardh and G. millardetii J. Agardh have been found in abundance along the Tanzanian coast (Jaasund, 1976). However, with the exception of G. cornea, information on biomass productivity of these algae is lacking. Besides, only three of these species have been shown to have potential for agar production. Semesi (1987) reported agar yield in the range of 28-48\% (dry weight) for G. cornea, G. corticata and G. fergusoni. More recently, Buriyo (1999) obtained maximum agar yield of $44 \%$ (dry weight) from $G$. cornea. The yield varied with season and the highest yield was obtained during the Northeast (NE) monsoon period.

Agar has many applications depending on its quality. Properties that determine its quality include the melting and gelling temperatures, gel strength, sulphate and the 3,6-anhydrogalactopyranose contents. Agar from Gracilaria species is widely used in food preparation.

Corresponding author: AKK.

E-mail: E-mail: akivaisi@amu.udsm.ac.tz 
We present here the standing stock seasonality of G. salicornia, which is the most abundant Gracilaria species in Tanzania, and report on investigations on the effects of alkali treatment on the yield and quality of its agar.

\section{MATERIALS AND METHODS}

\section{Study areas}

Collections were made at Oyster Bay, Dar es Salaam $\left(39^{\circ} 16^{\prime}-39^{\circ} 17.5^{\prime} \mathrm{E}\right.$ and $\left.6^{\circ} 46.5^{\prime} \mathrm{S}\right)$ and Chwaka Bay (39040'E , 6¹3'S) in Zanzibar. The Oyster Bay shore is characterised by a rocky platform backed by steep and overhanging cliffs. In the platform there are scattered boulders and rocky tidal pools of various sizes both of which form important habitats preferred by different macro- and micro-fauna and flora. Chwaka Bay samples were collected closer to the mangrove thicket, an area permanently submerged with a constantly running tidal stream. The major substrate for the algae is old Halimeda segments.

\section{Plant collection}

The algae were collected in 2002 during low spring tides in the inter-monsoon wet period (MarchApril), Southeast monsoon (July-August) and Northeast monsoon (November-December) periods. Sampling for biomass estimation was carried out according to Buriyo (1999). Environmental parameters namely light, water temperature and salinity were recorded during each sampling visit. In the laboratory, samples were sorted and washed thoroughly with tap water to remove rock debris and epiphytes. Plants for biomass determination were then dried in an oven at $105{ }^{\circ} \mathrm{C}$ to a constant weight. Plants for agar extraction were rinsed with tap water and dried first in the sun and then at $60{ }^{\circ} \mathrm{C}$ in an oven to constant weight.

\section{Agar extraction and quality determination}

Agar extraction was done according to the method described by Semesi (1979) and modified by Buriyo (1999). Alkali treatment of plants was carried out according to Oyieke (1993) with modification using a $5 \%$ (instead of $2 \%$ ) $\mathrm{NaOH}$. Agar extraction using an autoclave was done at $121{ }^{\circ} \mathrm{C}$ for 1 hour using $10 \mathrm{~g}$ dry sample in an Erlenmeyer flask filled with $500 \mathrm{ml}$ distilled water. Agar melting temperature and gel strength at $1.5 \%$ w/v was tested according to Oyieke (1993) and Buriyo (1999). Sulphate content was determined by a turbidimetric method as described in Allen (1989). The 3,6-anhydrogalactose sugar (3,6-AG) was determined by the resorcinol reagent method as described in Craigie \& Leigh (1978). The quality of standard agar (Oxoid Bacto Agar) prepared in the same manner was recorded for comparison.

\section{RESULTS}

\section{Seasonal variation in biomass and canopy cover}

The results for mean dry biomass and percentage canopy cover at Oyster Bay, Dar es Salaam are presented in Table 1. The highest mean biomass and canopy cover values $\left(59.8 \mathrm{~g} / \mathrm{m}^{2}\right.$ and $20.0 \%$, respectively) were obtained in April, and the lowest in December. Generally, biomass and percentage canopy cover were significantly higher during March-July and declined during NovemberDecember.

\section{Seasonal variation in agar yield}

The results for mean percentage agar yield are presented in Table 2. Agar yield varied from $16.35 \%$ in July to $30.2 \%$ in December in the Dar es Salaam samples and 13.7 to $28.0 \%$ in the Chwaka Bay samples. Generally agar yield at both stations was lower during April and July and higher

Table 1. Seasonal variation in biomass and canopy cover of Gracilaria salicornia at Oyster Bay, Dar es Salaam

\begin{tabular}{llrl}
\hline Month in 2002 & \multicolumn{2}{c}{ Biomass $\left(\mathrm{g} / \mathrm{m}^{2}\right)$} & Cover $(\%)$ \\
\hline March & $55.6 \pm 60.6$ & $18.55 \pm 20$ \\
April & $59.8 \pm 66$ & $20.00 \pm 22$ \\
July & $33.1 \pm 28$ & $11.06 \pm 9$ \\
August & $26.4 \pm 24$ & $8.81 \pm 8$ \\
November & $25.1 \pm 34$ & $8.35 \pm 11$ \\
December & $21.0 \pm 20$ & $7.00 \pm 6.7$ \\
\hline
\end{tabular}


in August and December. Statistical analysis (two sample t-test) showed that the agar yield was significantly higher during the NE monsoon period $(\mathrm{t}=2.9 ; \mathrm{P}=0.03)$ in samples collected from Oyster Bay. Agar yield did not differ significantly between seasons in samples collected from Chwaka Bay $(\mathrm{t}$ $=0.8 ; \mathrm{P}=0.4)$.

\section{Effect of alkali treatment and extraction method on agar yield}

Results of agar yield (\% dry wt) of plants treated and not treated with alkali $(5 \% \mathrm{NaOH})$ are presented in Table 2. With the exception of seaweeds harvested in August, alkali treatment reduced agar yield by almost $31-56 \%$ for Oyster Bay samples and 25-35\% for Chwaka Bay samples.

Different agar extraction methods appeared to affect the yield of agar. The comparison was arbitrary and was carried out using samples collected in November from Oyster Bay. Agar yield was about $7 \%$ (dry weight) higher for samples extracted by autoclaving at $121^{\circ} \mathrm{C}$ than those for samples extracted using a water bath at $95^{\circ} \mathrm{C}$. Agar extracted by using the autoclave method was also clearer than that extracted by the water bath method.

\section{Seasonal variation in agar properties}

Results of agar gel strength are presented in Fig.1. The native agar extracted from samples collected from Oyster Bay and Chwaka Bay had the highest gel strength during March and April, respectively. Agar from both populations also had generally higher gel strength during November and
December than during July to August.

Statistical analysis showed that gel strength in both populations was significantly higher during NE monsoon period $(\mathrm{t}=2.2 ; P=0.04$ and $\mathrm{t}=8.9$; $P<0.05$ for samples collected from Oyster Bay and Chwaka Bay, respectively). With the exception of July, alkali treatment significantly reduced gel strength of agar in both populations $(t=2.7 ; \mathrm{P}=$ 0.02 and $t=3.8 ; \mathrm{P}=0.007$ for samples collected from Oyster Bay and Chwaka Bay, respectively).
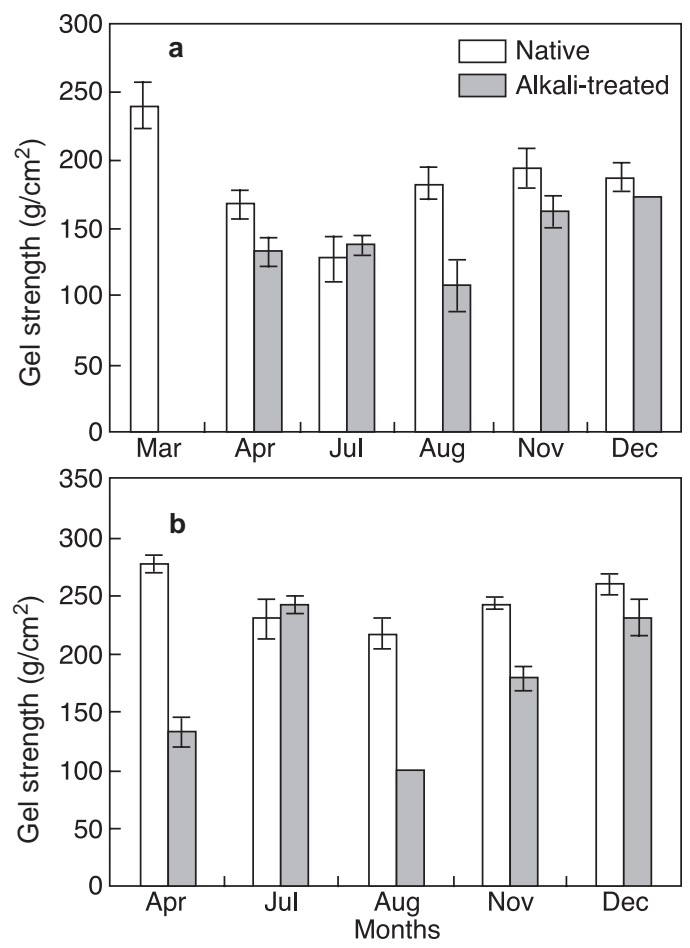

Fig. 1. Gel strength of native and alkali-treated agar extracted from $G$. salicornia harvested from (a) Oyster Bay in Dar es Salaam and (b) Chwaka Bay in Zanzibar in 2002

Table 2. Seasonal variation in agar yield ( $\%$ mean \pm s.d.) from native and alkali-treated Gracilaria salicornia $(\mathrm{n}=3)$

\begin{tabular}{lccccc}
\hline & \multicolumn{2}{c}{ Oyster Bay } & & \multicolumn{2}{c}{ Chwaka } \\
\cline { 2 - 3 } \cline { 5 - 6 } Month in 2002 & \multirow{2}{*}{ Native } & Alkali-treated & & Native & Alkali-treated \\
\hline March & $23.2 \pm 1.1$ & - & - & - \\
April & $22.6 \pm 2.0$ & - & & $14.1 \pm 0.9$ & - \\
July & $16.3 \pm 0.2$ & $7.0 \pm 2.2$ & & $13.7 \pm 1.0$ & $10.4 \pm 1.0$ \\
August & $27.6 \pm 2.4$ & $26.1 \pm 2.1$ & & $28.1 \pm 0.3$ & $22.3 \pm 3.2$ \\
November & $26.2 \pm 1.1$ & $17.6 \pm 0.4$ & & $20.3 \pm 0.6$ & $13.2 \pm 1.0$ \\
December & $30.2 \pm 1.6$ & $15.7 \pm 1.0$ & & $20.1 \pm 1.1$ & $15.7 \pm 0.6$ \\
\hline
\end{tabular}


Agar extracted from plants collected from Chwaka Bay had significantly higher gel strength than that extracted from plants collected from Oyster Bay, Dar es Salaam (Fig. 1), $(t=7.2 ; \mathrm{P}<<$ $0.05)$. There was a general decrease in gel strength during the rainy season, particularly April to August, although agar from samples collected from Chwaka Bay had highest gel strength in April. Overall, the mean gel strength of native agar samples $\left(205 \pm 45 \mathrm{~g} / \mathrm{cm}^{2}\right)$ was about $42 \%$ that of the standard agar used. The mean melting temperatures of the agar gels was in the range of $72-94{ }^{\circ} \mathrm{C}$. The highest melting point was measured for the native agar in April and the lowest for the gel from alkali-treated plants in August, both from Chwaka Bay.

The 3,6-anhydrogalactose and sulphate contents of both the native agar and alkali-treated agar are shown in Table 3. The 3,6anhydrogalactose content was highest during August for both populations and ranged from 16 to $44 \%$. High 3,6-anhydrogalactose content tended to coincide with low gel strength. Alkali treatment increased the amount of 3,6anhydrogalactose significantly in agar extracted from Chwaka Bay $(t=2.5 ; \mathrm{P}=0.02)$. On the other hand alkali treatment reduced significantly the amount of 3,6-AG in agar extracted from samples collected from Oyster Bay $(t=3 ; \mathrm{P}=0.008)$.
The sulphate content for native agar varied between $0.8-2.8 \%$ in native agar and $0.52-2.3 \%$ in alkali-modified agar from both populations.

\section{DISCUSSION}

\section{Seasonal variation in biomass and canopy cover}

The highest biomass recorded in this study was $59.8 \mathrm{~g} / \mathrm{m}^{2}$ (dry weight) during the SE monsoon period (March-July). This value is comparable to the highest biomass value (about $20 \mathrm{~g} / \mathrm{m}^{2}$ dry weight) obtained for the same algal species harvested from Negros Islands in the Philippines (Calumpong et al., 1999). However, these values seem too low for sustainable commercial exploitation, hence the need for cultivation studies.

The higher biomass and canopy cover recorded during the SE monsoon is probably due to improved nutrient availability after the long rains. Other factors which may also promote algal growth during this season are reduced light and temperature; March to July is associated with high cloud cover hence algal thalli are expected to be better protected from damaging light intensities than during September to December. High light intensity accompanied with high temperatures may reduce algal productivity partly due to

Table 3. 3,6 anhydrogalactose (3,6-AG) and sulphate content of native and alkali-treated agar from Gracilaria salicornia collected from Oyster Bay in Dar es Salaam and Chwaka Bay in Zanzibar

\begin{tabular}{|c|c|c|c|c|c|c|c|c|c|c|}
\hline Collection site & \multicolumn{2}{|c|}{ March } & \multicolumn{2}{|c|}{ April } & \multicolumn{2}{|c|}{ July } & \multicolumn{2}{|c|}{ August } & November & December \\
\hline \multicolumn{11}{|l|}{ Oyster Bay } \\
\hline \multicolumn{11}{|l|}{$\%$ 3,6-AG } \\
\hline Native & 26.3 & \pm 2.2 & 16.3 & \pm 1.5 & 26.0 & \pm 2.2 & 37.4 & \pm 0.4 & $34.1 \pm 3.1$ & $23.6 \pm 2.8$ \\
\hline Alkali-treated & & - & 18.1 & \pm 4.1 & 17.5 & \pm 1.3 & 30.0 & \pm 2.5 & $34.2 \pm 1$ & $19.6 \pm 2.7$ \\
\hline \multicolumn{11}{|l|}{$\%$ Sulphate } \\
\hline Native & 2.21 & \pm 0.9 & 2.7 & \pm 0.44 & 1.7 & \pm 0.45 & 2.33 & \pm 0.3 & $2.8 \pm 0.83$ & $2.25 \pm 0.85$ \\
\hline Alkali-treated & & - & 1.75 & \pm 0.61 & 0.9 & \pm 0.78 & 1.72 & \pm 0.28 & $2.33 \pm 0.6$ & $1.7 \pm 0.5$ \\
\hline \multicolumn{11}{|l|}{ Chwaka Bay } \\
\hline \multicolumn{11}{|l|}{$\%$ 3,6-AG } \\
\hline Native & & - & 24.9 & \pm 3.4 & 28.0 & \pm 3.4 & 44.0 & \pm 3.3 & $23.0 \pm 2.0$ & $19.4 \pm 3.0$ \\
\hline Alkali-treated & & - & 24.5 & \pm 3.5 & 35.7 & \pm 1.5 & 42.6 & \pm 3.0 & $25.8 \pm 1.7$ & $23.3 \pm 3.2$ \\
\hline \multicolumn{11}{|l|}{$\%$ Sulphate } \\
\hline Native & & - & 1.76 & \pm 0.42 & 0.8 & \pm 0.77 & 2.55 & \pm 0.3 & $2.41 \pm 0.62$ & $2.11 \pm 0.4$ \\
\hline Alkali-treated & & - & 0.97 & \pm 0.33 & 0.52 & \pm 0.5 & 1.81 & \pm 1.01 & $1.51 \pm 0.62$ & $0.98 \pm 0.5$ \\
\hline
\end{tabular}


photoinhibition (Krause \& Weis, 1991) and desiccation especially to intertidal algae. Moorjani (1982) found that on reef platforms of southern Kenya higher algal biomass occurred towards the end of the SE monsoon and reached a peak in September; that study emphasised that physical factors were responsible for the observed pattern and suggested that desiccation stress was less severe during the SE monsoon.

A gradual decrease in algal biomass and abundance was observed between August and December (Table 1). This period was associated with higher light intensities, temperatures and salinity. Furthermore, this period normally has relatively longer hours of sunshine (Buriyo, 1999). These conditions affect benthic intertidal organisms especially during the mid-day spring low tides. It was found (Buriyo, 1999) that during this period nitrogen in seawater was low $(<2$ $\mu$ g.at.N/12). The combined detrimental effects of light stress, desiccation, higher salinity and nutrient limitation probably resulted in the obseved decline of algal biomass.

\section{Seasonal variation in agar yield}

Agar yield varied with seasons and strains. Significantly higher mean agar yield in the studied populations was obtained during NE monsoon period. There was an inverse relationship between agar yield and biomass, with the highest agar yield being recorded during August-December and the lowest during April-July (Table 2). The environmental factors which coincided with higher agar yield were higher insolation, salinity, temperature (and low nitrogen availability, Buriyo 1999). The reason for this has not been established. Nevertheless, it is possible that during the period of favourable growth (SE monsoon), plants gradually accumulate resources such as nitrogen in order to survive the adverse period of low nutrients, elevated light intensity, temperature and salinity (i. e. NE monsoon period). In support of this hypothesis, Mshigeni (1974) found that during periods of high levels of nitrate concentration, algal photosynthates were diverted towards protein synthesis instead of polysaccharide synthesis. In a previous study (Buriyo, 1999) agar content in $G$. cornea was inversely correlated with nitrogen levels in seawater and thallus nitrogen and phosphorus. The inverse relationship between water nitrogen and biomass and agar yield has also been reported in Gracilaria (Lahaye and Rochas, 1991). Furthermore, Hoyle (1978) found that low agar yields in the winter were associated with higher total thallus nitrogen content in two Gracilaria species. Other studies supporting the observations are those of DeBoer (1979); Lahaye $\&$ Yaphe (1988); Bird (1988) and Oyieke (1993).

The low agar content observed from April to July may also be related to the onset of the long rains of the SE monsoon. During the rainy season, factors which may contribute to low agar content include low light due to high cloud cover and low salinity. The stress imposed by low salinity might have resulted into the channelling of photosynthetic by-products to sugars responsible for maintaining ionic balance. Moreover lack of adequate $\mathrm{CO}_{2}, \mathrm{HCO}_{3}{ }^{-}$and $\mathrm{Ca}^{2+}$ in rainwater, may also have a considerable effect on photosynthesis (Lobban \& Harrison, 1994; Yarish et al., 1980), and therefore low level of carbohydrate accumulation. Another possibility is the loss of polysaccharides by cellular exudation as a result of stress. It has been reported (Moebus \& Johnson, 1974; Moebus et al., 1974; Harlin \& Craigie, 1975) that under stress, seaweeds exude more than $1 \%$ of their net assimilation. Also exudation of $30-40 \%$ of net assimilation has been reported (Lobban \& Harrison, 1994). Other studies corroborating this finding include the work of Santelices \& Varela (1993) who analysed the culture media used to culture Gracilaria chilensis at low light intensity and temperature $\left(45 \mu \mathrm{mol}\right.$ photons $/ \mathrm{m}^{2} / \mathrm{s}$ and $\left.14^{\circ} \mathrm{C}\right)$ and found a mixture of polysaccharides in which highly sulphated galactans were the most dominant. Furthermore, Ekman \& Pedersén (1990) reported that stressful cultivation conditions such as those induced by low light availability may stimulate carbon excretion and increase the coldwater-soluble fraction of the agar.

The agar composition of Gracilaria has been reported to be species-dependent (Nelson et al., 1983; Yaphe, 1984) and influenced by seasons (Asare, 1980; Lahaye \& Yaphe, 1988).

In this study G. salicornia from Oyster Bay yielded more agar than that from Chwaka. The difference in agar yield between these populations 
may be attributed to the ecology of the two sites. For instance, salinity at Oyster Bay fluctuated between 34-38\%o in the water column and 25-30 $\% o$ in tidal pools exposed to rain during low tides, while at Chwaka Bay it was 33-35\%o during the study period. Furthermore, samples collected from Chwaka Bay were permanently submerged hence less exposed to environmental parameter fluctuations. From the previous discussion, the exposure of algae to environmental parameter fluctuations may affect their agar content. The differences in agar yield between the two populations could also be due to the differences in the strains of G. salicornia found at Oyster Bay and Chwaka Bay. We observed that populations occurring at the former site were constricted while those at the latter were not.

Alkali treatment significantly affected agar yield as is well known from the literature. The results of the alkali-treated plants suggest that hotwater-soluble polysaccharides that are extracted from alkali-treated plants of $G$. salicornia contain important quantities of alkali-labile sulphates, some of which may have been lost during the processing. These results agree with those reported by Oyieke (1993) on the same species.

The agar yield from plants extracted by autoclaving at $121^{\circ} \mathrm{C}$ was slightly higher than that from plants extracted at $95{ }^{\circ} \mathrm{C}$ in the water bath. The former method was less time-consuming and the resulting agar's clarity was better.

\section{Seasonal variation in agar quality}

Higher gel strengths were observed in March for samples collected from Oyster Bay and in April for samples collected from Chwaka Bay compared to July and August. Although March and April are normally rainy months, and July and August are dry along the Tanzanian coast, the situation was the opposite in 2002 when this study was conducted. The occurrence of agar with higher gel strength during the dry period and vice versa has been reported by other workers (Abbott, 1980; Asare, 1980).

The generally low gel strength observed during the rainy season could be related to low salinity, which may result in greater osmotic gradient such that ions like $\mathrm{Ca}^{2+}$ and $\mathrm{K}^{+}$(Yarish et al., 1980) leave the cell to the medium (Lobban \& Harrison, 1994). These ions have been reported (Grant et al., 1973; Semesi, 1979) to increase gel strengths of some algal polysaccharides such as alginates from brown algae and other gels from red algal species such as Eucheuma, Gracilaria, Hypnea, etc. Moreover, Bird (1988) reported low gel strength from agar extracted from Gracilaria species cultivated at low salinity (17\%o).

The 3,6-AG content varied between treatments, sites and months, but was high in all samples during August, which coincided with low agar gel strengths. To the contrary, high 3,6-AG content has been previously reported to increase gel strength. Alkali treatment of either algal plants or agar has been shown to reduce sulphate, increase 3,6-AG content and hence increase gel strength in some Gracilaria species (Yenigül, 1993; Chirapart \& Ohno, 1993; Givernaud et al., 1999; Montaño et al., 1999). It therefore appears that gel strength is not solely dependent on the 3,6-AG content.

In the present study, alkali treatment slightly reduced 3,6-AG content but had little effect on the sulphate content. These results are in conformity with those obtained for G. caudata from Brazil and G. tenuistipitata from China (Macchiavello et al., 1999). The presence of high sulphate content in tropical agarophytes has been reported to affect greatly its agar quality. It has also been reported (Lignell \& Pedersén, 1989) that the content of 3,6AG decreased while that of sulphate and 4-Omethyl-L-galactose increased in Gracilaria tikvahiae cultivated at higher temperatures. The more sulphated chains have the greater tendency to enter into solution (Rees, 1972; Tsuneaki \& Suzuki, 1975). As such, the association of agar chains during gelation is inhibited by increasing the sulphate content.

Lower gel strengths and higher sulphation levels have also been reported for samples grown during summer or at high temperatures (Hoyle, 1978; Cote \& Hanisak, 1986). However, Wang \& Yang (1980), Abbott (1980) and Asare (1980) all reported high gel strengths for agar extracted from samples collected in summer with temperatures higher than $30^{\circ} \mathrm{C}$. In the present study there was no clear relationship between the variations in sulphate and 3,6-AG contents and gel strength. These observations from the literature and the 
present study suggest that none of the single factors tested significantly affects gel properties.

Other factors which influence agar quality include nutrient status of the media in which algae grow (Bird, 1988; Chiles et al., 1989), age (Lignell \& Pedersén, 1989) and reproductive status of the plants (Givernaud et al., 1999), molecular weight of the polymer (McKinnon et al., 1969), concentration of cations such as $\mathrm{K}^{+}$(McKinnon, 1973), methoxyl content (Arnott et al., 1974a), pyruvic acid (Arnott et al., 1974b), the concentration of alkali for seaweed treatment prior to extraction.

Since all of the factors enumerated above were not investigated in this study, their effects on our agar quality results cannot be discussed. Furthermore, different concentrations of alkali have been employed to treat seaweeds before extractions; hence it is difficult to compare its effect. There are also seasonal differences between locations and years in the magnitude and timing of the environmental parameters affecting algal growth.

\section{CONCLUSIONS}

The best period for harvesting wild populations of G. salicornia for agar production in Tanzania is during the dry NE monsoon. However, the low biomass measured during this period might be a constraint to the exploitation of this agarophyte unless it is cultivated. Besides, as its agar quality is below the standard for commercial bacteriological agar, it can be only used in applications that require soft gels unless its quality is improved.

Acknowledgement-This study was supported by a grant from Sida/SAREC under the Co-Support Fund to the Faculty of Science, University of Dar es Salaam

\section{REFERENCES}

Abbott, I.A. (1980) Some field and laboratory studies on colloid producing red algae in central California. Aquat. Bot. 8: 255-266.

Allen, S. E. (Ed.) (1989) Chemical analysis of ecological materials. 2nd edn. Blackwell Scientific Publications. pp. 46-76.

Armisen R. (1995) World-wide use and importance of Gracilaria. J. Appl. Phycol.7: 231-243.

Arnott, S., Fulmer, A., Scott, W.E., Dea, I.C.M.,
Moorhouse, R. \& Rees, D.A. (1974a) The agarose double helix and its function in agarose gel structure. J. Mol. Biol. 90: 269-284.

Arnott, S., Scott, W.E., Rees, D.A. \& McNab, C.G.A. (1974b) $i$-carrageenan: molecular structure and packing of polysaccharide double helices in oriented fibres of divalent cation salts. J. Mol. Biol. 90: $253-267$.

Asare, S.O. (1980) Seasonal changes in sulphate and 3,6 anhydrogalactose content of phycocolloids from two red algae. Bot. Mar. 23: 595-598.

Bird, K.T. (1988) Agar production and quality from Gracilaria sp. strain G-16: effects of environmental factors. Bot. Mar. 31: 33-39.

Buriyo, A.S. (1999) The effect of seasons on yield and quality of agar and carrageenan from selected Tanzanian red algal species. MSc thesis. University of Dar es Salaam.

Buriyo, A.S., Oliveira, E.C., Mtolera, M.S.P. \& Kivaisi, A.K. (in press) Occurrence and distribution of the genus Gracilaria (Gracilariales, Rhodophyta) in Tanzania. Western Indian Ocean J. Mar. Sci. In press.

Buschmann, A.H. \& Correa, J.A. (2001) Red algal farming: a review. Aquaculture 194: 203-220.

Calumpong, H.P., Maypa, A., Magbanua, M. \& Suarez, P. (1999) Biomass and agar assessment of three species of Gracilaria from Negros island, Central Philippines. Hydrobiologia 398/399: 173-182.

Chiles, T.C., Bird, K.T. \& Koehn, F.E. (1989) Influence of nitrogen availability on agar polysaccharides from Gracilaria verrucosa, strain G-16: structural analysis by NMR spectroscopy. J. Appl. Phycol., 1: 59-65.

Chirapart, A. \& Ohno, M. (1993) Seasonal variation in the physical properties of agar and biomass of Gracilaria sp. (chorda type) from Tosa Bay, southern Japan. Hydrobiologia 260/261: 541-547.

Cote, G.L. \& Hanisak, M.D. (1986) Production and properties of native agars from Gracilaria tikvahiae and other red algae. Bot. Mar. 29: 359-366.

Craigie, J.S. \& Leigh, C. (1978) Carrageenans and agars. In: Hellebust, J.A. \& Craigie, J.S. (eds) Handbook of phycological methods, physiological and biochemical methods. Cambridge University Press, London. pp. 114-116.

Critchley A.T. (1997) Introduction: seaweed resources. In: Ohno, M. \& Critchley, A. T. (eds). Seaweed cultivation and marine ranching. Japanese International Collaboration Agency (JICA), Yokosuka. pp. 1-7.

DeBoer, J.A. (1979) Effects of nitrogen enrichment on growth rate and phycocolloid content in Gracilaria foliifera and Neoagardhiella baileyi (Florideophyceae). Proc. Int. Seaweed Symp. 9: 263-271. Science Press, Princeton.

Ekman, P. \& Pedersén, M. (1990) The influence of 
photon irradiance, day length, dark treatment, temperature and growth rate on the agar composition of Gracilaria sordida (Hudson) Papenfuss (Gigartinales). Bot. Mar. 33: 483-495.

Givernaud, T., Gourji, A.E., Givernaud, A.M., Lemoine, Y. \& Chiadmi, N. (1999) Seasonal variations of growth and agar composition of Gracilaria multipartita harvested along the Atlantic coast of Morocco. Hydrobiologia 398/ 399: $167-172$.

Grant, G.T., Morris, E.R., Rees, D.A., Smith, P.J.C. \& Thom, D. (1973) Biological interactions between polysaccharides and divalent cations. The egg-box model. Febs Letters 32: 195-198.

Harlin, M.M. \& Craigie, J.S. (1975) The distribution of photosynthate in Ascophyllum nodosum as it relates to epiphytic Polysiphonia lanosa. J. Phycol. 11: $109-113$.

Hoyle, M.D. (1978) Agar studies in two Gracilaria species (G. bursapastoris (Gmelin) Silva and $G$. coronopifolia J. Ag.) from Hawii II. Seasonal aspects. Bot. Mar. 21: 347-352.

Jaasund, E. (1976) Intertidal seaweeds in Tanzania. A field guide. 1st edition. University of Troms $\varnothing$.

Krause, G.H. \& Weis, E. (1991) Chlorophyll fluorescence and photosynthesis: the basics. Ann. Rev. Plant Physiol. Plant Mol. Biol. 42: 313-349.

Lahaye, M. \& Rochas, C. (1991) Chemical structure and physico-chemical properties of agar. Hydrobiologia 221: 137-148.

Lahaye, M. \& Yaphe, W. (1988) Effects of seasons on the chemical structure and gel strength of Gracilaria pseudoverrucosa agar (Gracilariaceae, Rhodophyta. Carbohyd. Polymers 8: 285-301.

Lewis J.G., Stanley, N.F \& Guist, G.G.. (1990) Commercial production and applications of algal hydrocolloids. In: Lembi, C.A. \& Waaland, J.R. (eds). Algae and human affairs. Cambridge University Press, Cambridge. pp. 205-235.

Lignell, A. \& Pedesén, M. (1989) Effects of pH and inorganic carbon concentrations on growth of Gracilaria secundata. Br. Phycol. J. 24: 83-89.

Lobban, C.S. \& Harrison, P.J. (1994) Seaweed ecology and physiology. Cambridge University Press, $366 \mathrm{pp}$.

Macchiavello, J., Saito, R., Garofalo, G. \& Oliveira, E.C. (1999) A comparative analysis of agarans from commercial species of Gracilaria (Gracilariales, Rhodophyta) grown in vitro. Hydrobiologia 398/399: 397-400.

McKinnon, A.A. (1973) Formation, melting and interaction of polysaccharide helices. Ph.D. thesis. University of Edinburgh.

McKinnon, A.A., Rees, D.A. \& Williamson, F.B. (1969) Coil to double helix transition for a polysaccharide. Chem. Commun. 13: 701-702.

Moebus, K. \& Johnson, K.M. (1974) Exudation of dissolved organic carbon by brown algae. Mar.
Biol. 26: $117-125$.

Moebus, K., Johnson, K.M. \& Sieburth, J.M. (1974) Rehydration of desiccated intertidal brown algae: release of dissolved organic carbon and water uptake. Mar. Biol. 26: 127-134.

Moorjani, S.A. (1982) Rocky shores zonation in Kenya: horizontal and vertical distribution patterns in the marine flora. Proc. Symp. Coast. \& Mar. Envir. Red Sea, Gulf of Aden and Trop. West. Indian Ocean, Vol. 2. AESCO/UNESCO, Khartoum.

Montaño, N. E., Villanueva, R.D. \& Romero, J.B. (1999) Chemical characteristics and gelling properties of agar from two Philippine Gracilaria spp. (Gracilariales, Rhodophyta). J. Appl. Phyc. 11: $27-34$.

Mshigeni, K.E. (1974) The biology and ecology of selected Hawaiian Hypneaceae (Rhodophyta, Gigartinales). Vols 1 and 2. Ph.D. dissertation. The University of Hawaii.

Nelson, S.G., Yang, S.S., Wang, C.Y. \& Chiang, Y.M. (1983) Yield and quality of agar from species of Gracilaria (Rhodophyta) collected from Taiwan and Micronesia. Bot. Mar. 26: 331-336.

Oliveira, E. C., Alveal, K. \& Anderson, J. R. (2000) Mariculture of the agar-producing gracilarioid red algae. Rev. Fish. Sci. 8: 345-377.

Oyieke, H. A. (1993) The yield, physical and chemical properties of agar gel from Gracilaria species (Gracilariales, Phodophyta) of the Kenya coast. Hydrobiologia 260/261: 613-620.

Rees, D.A. (1972) Shapely polysaccharides. Biochem. J. 126: 257-273.

Santelices, B. \& Varela, D. (1993) Exudates from Gracilaria chilensis stimulate settlement of epiphytic ulvoids. Hydrobiologia 260/261: 327-333.

Semesi, A.K. (1979) Studies on industrial polysaccharides from selected Tanzanian marine algae. Ph. D. thesis. University of Dar es Salaam.

Semesi, A.K. (1987) Agar from three Gracilaria species from Tanzania. Tanzania J. Science 13: 1-13.

Tsuneaki, F. \& Suzuki, T. (1975) Preparation and properties of agar sulphates. Agric. Biol. Chem. 39: 119-126.

Wang, C. \& Yang, S. (1980) Seasonal variations of the quality of Gracilaria cultivation in Taiwan. Proc. Natl. Sci. Council R.O.C, 4: 78-86.

Yaphe, W. (1984) Properties of Gracilaria agars. Hydrobiologia 116/117: 171-186.

Yarish, C., Edwards, P. \& Casey, S. (1980) The effects of salinity, and calcium and potassium variation on the growth of two estuarine red algae. J. Exp. Mar. Biol. Ecol. 47: 235-249.

Yenigul, M. (1993) Seasonal changes in the chemical, and gelling characteristics of agar from Gracilaria verrucosa collected in Turkey. Hydrobiologia 260/ 261: 627-631. 